\title{
Downregulation of RNA binding motif protein 17 expression inhibits proliferation of hypopharyngeal carcinoma FaDu cells
}

\author{
YUEFENG HAN, MINGJIE ZHANG, DESHANG CHEN, HUI LI, XIAOMIN WANG and SHIYIN MA \\ Department of Otorhinolaryngology Head and Neck Surgery, The First Affiliated Hospital of Bengbu Medical College, \\ Bengbu, Anhui 233000, P.R. China
}

Received August 26, 2016; Accepted December 12, 2017

DOI: $10.3892 / \mathrm{ol} .2018 .8012$

\begin{abstract}
RNA binding motif protein 17 (RBM17) is a protein-coding gene. The protein encoded by $R B M 17$ is involved in the regulation of alternative splicing and is overexpressed in cancer. The present study aimed to determine the effect of RBM17-knockdown in hypopharyngeal carcinoma FaDu cells using the lentivirus-mediated shRNA method. Cell proliferation was detected by an MTT assay. Flow cytometry analysis was used to determine cell cycle distribution and apoptosis. The results of the present study demonstrated that $R B M 17$ expression was significantly decreased in $\mathrm{FaDu}$ cells infected with lentivirus-shRNA. Knockdown of RBM17 expression by shRNA significantly reduced cell proliferation, augmented cell apoptosis and arrested cells at the $\mathrm{G}_{2} / \mathrm{M}$ phase in $\mathrm{FaDu}$ cells. The results of the present study indicate that RBM17 serves a notable role in cell proliferation, cell cycle progression and apoptosis of hypopharyngeal carcinoma cells.
\end{abstract}

\section{Introduction}

Hypopharyngeal cancer is a common malignant tumor, which has a poor prognosis among head and neck cancer $(1,2)$. Hypopharyngeal carcinoma originates in the mucosal epithelia in the hypopharynx (3-5). Hypopharyngeal cancer is invasive, yet the majority of patients exhibit a lack of evident early symptoms (6). In addition, the hypopharynx is not part of routine medical exams, thus the majority of patients with hypopharyngeal cancer exhibit advanced disease at diagnosis (7); the 5-year survival rate is $<20 \%$ for patients with advanced disease (8). Surgery, chemotherapy and radiotherapy are used in combination in the clinical treatment of hypopharyngeal cancer; however, outcomes of these treatments are not

Correspondence to: Dr Yuefeng Han, Department of Otorhinolaryngology Head and Neck Surgery, The First Affiliated Hospital of Bengbu Medical College, 287 Changhuai Road, Bengbu, Anhui 233000, P.R. China

E-mail: hanyf1015@126.com

Key words: RNA binding motif protein 17, hypopharyngeal carcinoma, cell proliferation, apoptosis satisfactory $(9,10)$. Therefore, the development of novel strategies and effective methods to treat hypopharyngeal cancer is imperative.

Alternative splicing has a powerful role in regulating gene expression and increasing protein diversity $(11,12)$. Alternative splicing is performed by heterogeneous nuclear ribonucleoprotein and splicing factor proteins (13-15). RNA-binding motif protein 17 (RBM17), which is a part of the RNA spliceosome complex (16), binds to the single-stranded three AG dinucleotides at the exon/intron border, and acts in the second catalytic step of mRNA splicing (17). The N-terminal domain of RBM17 contains a G-patch that has been implicated in an interaction between proteins and protein/nucleic acid $(18,19)$, and the C-terminal domain contains an RNA recognition motif for mRNA splicing (17). RBM17 is also involved in DNA repair (20). Expression of RBM17 is low in normal tissues, including those of the breast, liver and prostate; however, its overexpression has been found in a number of solid tumor types including breast, pancreas and prostate cancer (21). However, the role of RMP17 in hypopharyngeal carcinoma remains unclear.

The present study investigated the effects of RBM17-knockdown on cell proliferation, cell cycle and apoptosis in the hypopharyngeal carcinoma cell line FaDu using lentivirus-mediated specific shRNA targeting RBM17.

\section{Materials and methods}

Cell culture. FaDu cells were purchased from Cell Bank of Chinese Academy of Science (Shanghai, China) and cultured in Dulbecco's modified Eagle's medium (DMEM) supplemented with $10 \%$ fetal bovine serum, $100 \mathrm{IU} / \mathrm{ml}$ penicillin and $100 \mu \mathrm{g} / \mathrm{ml}$ streptomycin (Sangon Biotech Co. Ltd, Shanghai, China). Cells were maintained in an incubator with $5 \% \mathrm{CO}_{2}$ and $95 \%$ humidity at $37^{\circ} \mathrm{C}$. FaDu cells were infected with the lentiviral vectors containing small interfering RNAs (siRNAs) targeting $R B M 17$ or empty vectors.

Lentiviral construction for shRNA treatment. RBM17-specific shRNA (5'-ACT TAAGTGTCCTACTAAA-3'; GenBank NM_032905) and the negative control sequence (5'-AAT TCTCCGAACGTGTCACGT-3') were cloned into AgeI and EcoRI sites of the pGV115-green fluorescent protein (GFP) lentiviral vector (Shanghai Genechem Co., Ltd., Shanghai, 
China). The plasmids used were pGV115-GFP-shRBM17 for specific interference of $R B M 17$ and pGV115-GFP-negative control (NC) for control. Inhibition of RBM17 expression in FaDu cells with $R B M 17$-specific shRNA was performed as follows. Lentivirus was generated in FaDu cells as described previously (22). Briefly, FaDu $\left(2 \times 10^{5}\right.$ cells/well) cells were seeded into 6-well plates; when cell growth reached $\sim 80 \%$ confluency, appropriate volumes of lentiviral vectors were transfected into FaDu cells for 48-72 h to generate lentivirus. Lentivirus was harvested and the viral titer was measured with a Centricon-plus-20 (EMD Millipore, Billerica, MA, USA). The cells were used in subsequent experiments when the rate of infected cells reached $70 \%$ at $72 \mathrm{~h}$ post-infection.

Human FaDu cells $\left(2 \times 10^{5}\right.$ cells/well) were reseeded into 6-well plates and incubated with either a RBM17-shRNA $\left(1 \times 10^{6} \mathrm{TU}\right)$ or control-payload lentiviruses $\left(1 \times 10^{6} \mathrm{TU}\right)$ for 8-12 h. A total of $72 \mathrm{~h}$ post-infection, infected FaDu cells were observed under a fluorescent imaging microscope (Olympus Corporation, Tokyo, Japan) at x100 magnification by counting green cells based on GFP intensity. The efficiency of this infection was determined by RT-PCR and western blotting, which were performed according to the subsequent steps.

Cell proliferation assay. FaDu cells were infected with $R B M 17$ shRNA lentivirus (shRBM17) or non-silencing shRNA lentivirus, and $2 \times 10^{3}$ cells were seeded with $100 \mu 1$ medium/well into 96-well plates. Cell growth and viability was evaluated on days 1, 2, 3, 4 and 5. For cell growth, FaDu cells at the logarithmic phase after being infected with either the shCtrl or shRBM17 lentivirus and the plates were counted using the Cellomics ArrayScan ${ }^{\mathrm{TM}}$ VT1 automated reader (Cellomics, Inc.; Thermo Fisher Scientific, Inc., Waltham, MA, USA) for each day. In each well, $\geq 800$ cells were analyzed. Each experiment was performed in triplicates. For cell viability, at the given time, $20 \mu \mathrm{l}$ MTT ( $5 \mathrm{mg} / \mathrm{ml}$; Sangon Biotech Co., Ltd.) was added into each well and plates were incubated for $4 \mathrm{~h}$ at $37^{\circ} \mathrm{C}$. The medium in each well was then removed and crystals were dissolved by the addition of $150 \mu \mathrm{l}$ dimethyl sulfoxide (Sangon Biotech Co., Ltd.) in each well. Following a $10 \mathrm{~min}$ incubation at room temperature, the absorbance was measured at $570 \mathrm{~nm}$.

Reverse transcription-quantitative polymerase chain reaction. Total RNA was isolated from the FaDu cell lines using TRIzol ${ }^{\circledR}$ reagent (Invitrogen; Thermo Fisher Scientific, Inc.). Total RNA was used in a reverse transcription reaction to synthesize cDNA according to the manufacturer's protocol using RevertAid ${ }^{\circledR}$ First Strand cDNA Synthesis Kit (MBI Fermantas; Thermo Fisher Scientific, Inc.). PCR primers were designed by Beacon Designer 7 software (Premier Biosoft International, Palo Alto, CA, USA). Primer sequences were as follows: RBM17 forward, 5'-TCAAATCCGCTG ACTGAAATAC-3' and reverse, 5'-ACCTCCCATTCAAGT CAACAA-3'; and GAPDH forward, 5'-TGACTTCAACAG CGACACCCA-3' and reverse, 5'-CACCCTGTTGCTGTA GCCAAA-3'. Quantitative PCR was performed according to Takara SYBR ${ }^{\circledR}$ Master Mix kit instructions (Takara Biotechnology Co., Ltd, Dalian, China) as following: $95^{\circ} \mathrm{C}$ for $15 \mathrm{sec}$, followed by 45 cycles of $95^{\circ} \mathrm{C}$ for $5 \mathrm{sec}$ and $60^{\circ} \mathrm{C}$ for
$20 \mathrm{sec}$. The $2^{-\Delta \Delta \mathrm{Cq}}$ method was used to analyze relative changes in gene expression (23).

Flow cytometry analysis of cell cycle distribution. For cell cycle analysis, cells infected with RBM17-shRNA lentivirus or $\mathrm{NC}$ lentivirus were seeded in 6-well plates and cultured at $37^{\circ} \mathrm{C}$ for 5 days prior to analysis. Cells were collected by centrifugation at $1,200 \mathrm{x}$ g for $5 \mathrm{~min}$ at $4^{\circ} \mathrm{C}$, washed twice with ice-cold PBS, fixed with cold $70 \%$ ethanol for $1 \mathrm{~h}$ at $4^{\circ} \mathrm{C}$, and stained with $50 \mu \mathrm{g} / \mathrm{ml}$ propidium iodide (PI) (Sigma-Aldrich; Merck KGaA, Darmstadt, Germany) in the presence of $100 \mu \mathrm{g} / \mathrm{ml}$ RNase (Sangon Biotech Co., Ltd.) at $37^{\circ} \mathrm{C}$ for $30 \mathrm{~min}$. Cells were analyzed by flow cytometry using a FACSCalibur ${ }^{\mathrm{TM}}$ flow cytometer (BD Biosciences, San Diego, CA, USA), according to the manufacturer's protocol. Data was analyzed using FlowJo Software (version 10; FlowJo LLC, Ashland, OR, USA).

Analysis of apoptosis by flow cytometry. To analyze apoptosis, cells were stained with binding buffer containing annexin V-allophycocyanin (cat. no. 88-8007; eBioscience, San Diego, CA, USA) at $25^{\circ} \mathrm{C}$ in the dark for $10 \mathrm{~min}$. Cells were analyzed by flow cytometry using a FACSCalibur flow cytometry (BD Biosciences) according to the manufacturer's protocol. Data was analyzed using FlowJo Software (version 10; FlowJo LLC).

Western blot analysis. FaDu cells were lysed and homogenized on ice in lysis buffer (cat. no. C500001; Sangon Biotech). Homogenates were centrifuged at $12,000 \times \mathrm{g}$ for $20 \mathrm{~min}$ at $4^{\circ} \mathrm{C}$. The protein concentration of each sample was measured using Modified BCA Protein Assay Kit (cat. no. C503051; Sangon Biotech). Equal volumes ( $20 \mu \mathrm{g}$ total soluble proteins of supernatants) were separated on $12 \%$ SDS-PAGE gels and transferred onto polyvinylidene difluoride membranes. Membranes were incubated with rabbit polyclonal antibody specific for RBM17 (1:500; cat. no. 101441; Abcam, Cambridge, UK) and monoclonal antibody specific for GAPDH $(1: 2,000$, cat. no. sc-32233; Santa Cruz Biotechnology, Inc., Dallas, TX, USA) overnight at $4^{\circ} \mathrm{C}$. Membranes were then rinsed 3 times and incubated with horseradish peroxidase-conjugated goat anti-rabbit IgG antibody (1:10,000, cat. no. sc-2005; Santa Cruz Biotechnology, Inc.) at room temperature for $1 \mathrm{~h}$. Membranes were visualized using an EasyBlot ECL kit (Bio Basic Inc., Markham, ON, Canada).

Statistical analyses. Data were expressed as mean \pm standard deviation. Student's t-test was performed to analyze differences between two groups using SPSS 16.0 software (SPSS Inc., Chicago, IL, USA). P $<0.05$ were considered to indicate a statistically significant difference.

\section{Results}

RBM17 mRNA and protein is knocked down in cells infected with RBM17-shRNA. A high infection efficiency was observed by measuring GFP expression via fluorescence microscopy (Fig. 1A). Expression of RBM17 mRNA in cells infected with $R B M 17-$ siRNA was significantly decreased compared with control cells $(\mathrm{P}<0.01$; Fig. 1B). Western blot analysis revealed 

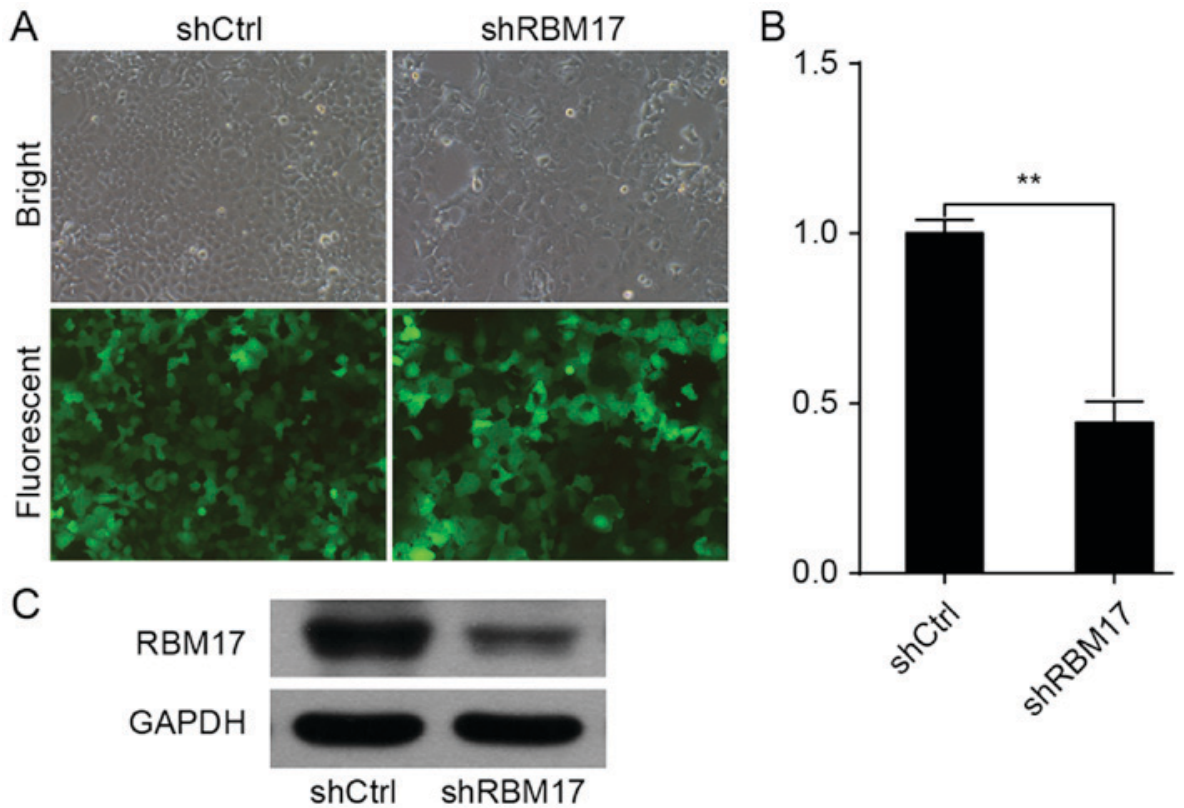

Figure 1. Expression of RBM17-knockdown in hypopharyngeal carcinoma cell line FaDu. (A) Representative images of cells in culture taken 3 days post-infection using light and fluorescent microscopy are shown. Original magnification, $\mathrm{x} 100$. (B) At 5 days post-infection, RBM17 mRNA expression was significantly reduced in FaDu RBM17-shRNA knockdown cells as compared with FaDu shCtrl cells $\left({ }^{* *} \mathrm{P}<0.01\right)$. (C) RBM17 protein expression analyzed by western blot analysis in shCtrl and shRBM17 groups. GAPDH was used as the internal control. RBM17, RNA binding motif protein 17; shCtrl, control short hairpin RNA.

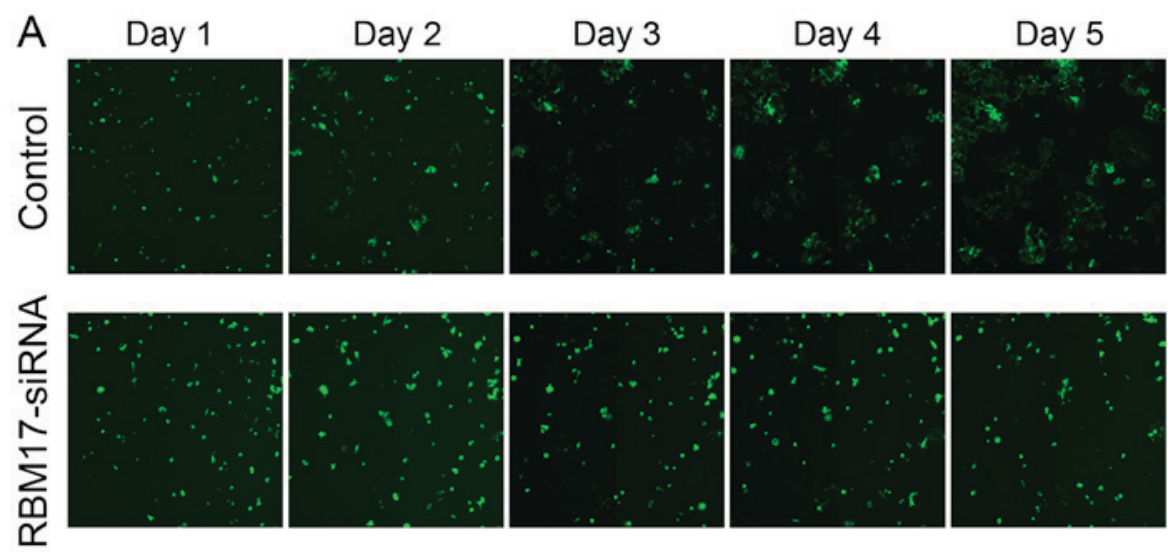

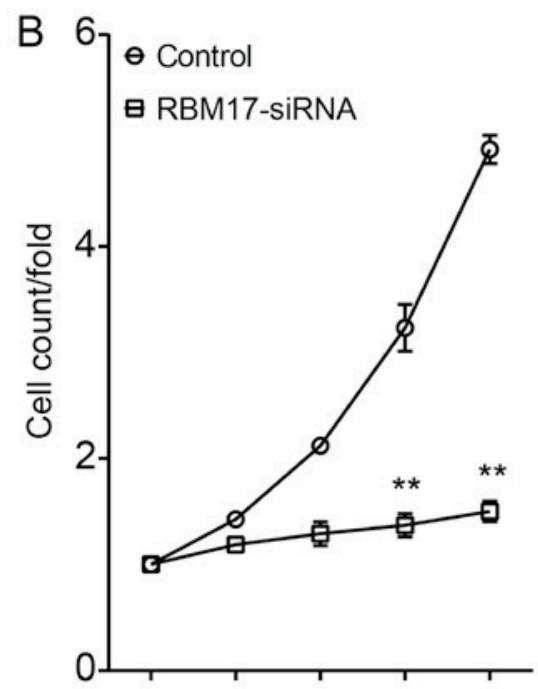

Day 1 Day 2 Day 3 Day 4 Day 5

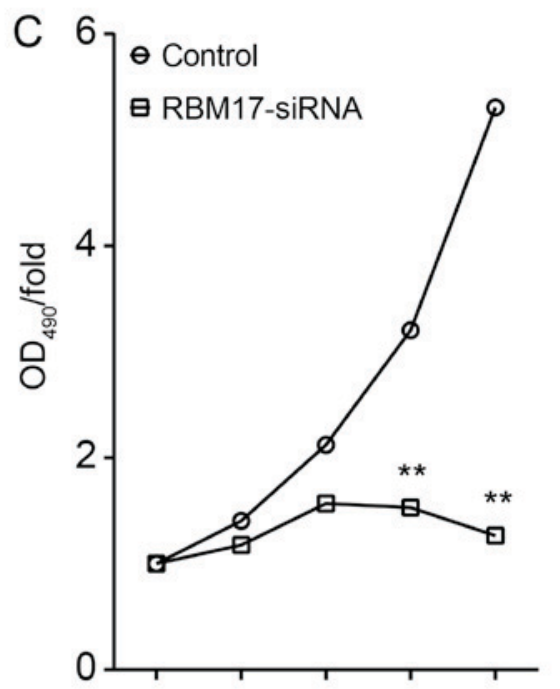

Day 1 Day 2 Day 3 Day 4 Day 5

Figure 2. Effect of RBM17 expression on proliferation of hypopharyngeal carcinoma cells. (A) Images of cell growth (initial magnification, x100). (B) Human hypopharyngeal carcinoma cell growth was assayed every day for 5 days. (C) The cell growth rate was monitored on days 1,2,3,4 and 5 by assay. shCtrl vs. shRBM17, ${ }^{* *} \mathrm{P}<0.01$. RBM17, RNA binding motif protein 17; shCtrl, control short hairpin RNA; OD, optical density. 

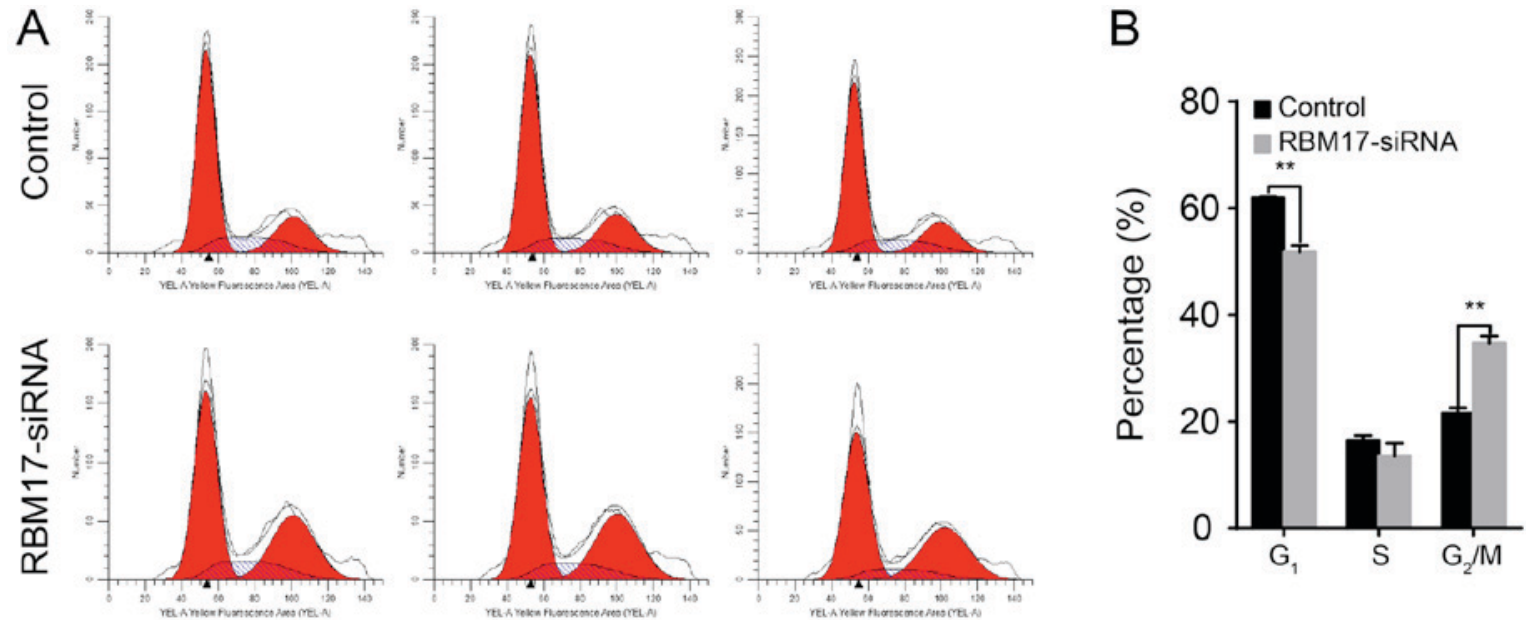

Figure 3. Effects of RBM17-knockdown on the cell cycle. (A) Cell cycle analysis of FaDu cells was determined by flow cytometry. (B) The proportion of different cell cycle phases. The proportion of cells in the $\mathrm{G}_{2} / \mathrm{M}$ phase is significantly increased in cells infected with $R B M 17$-siRNA ( $\left.{ }^{* *} \mathrm{P}<0.01\right)$. RBM17, RNA binding motif protein 17; siRNA, small interfering RNA.
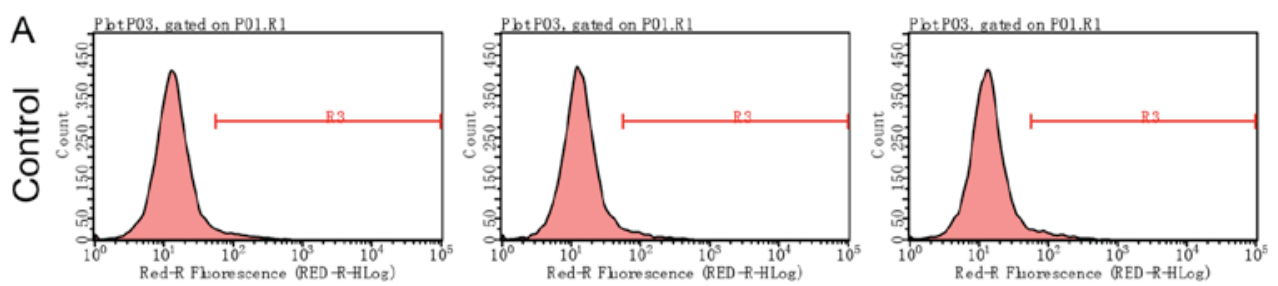

B
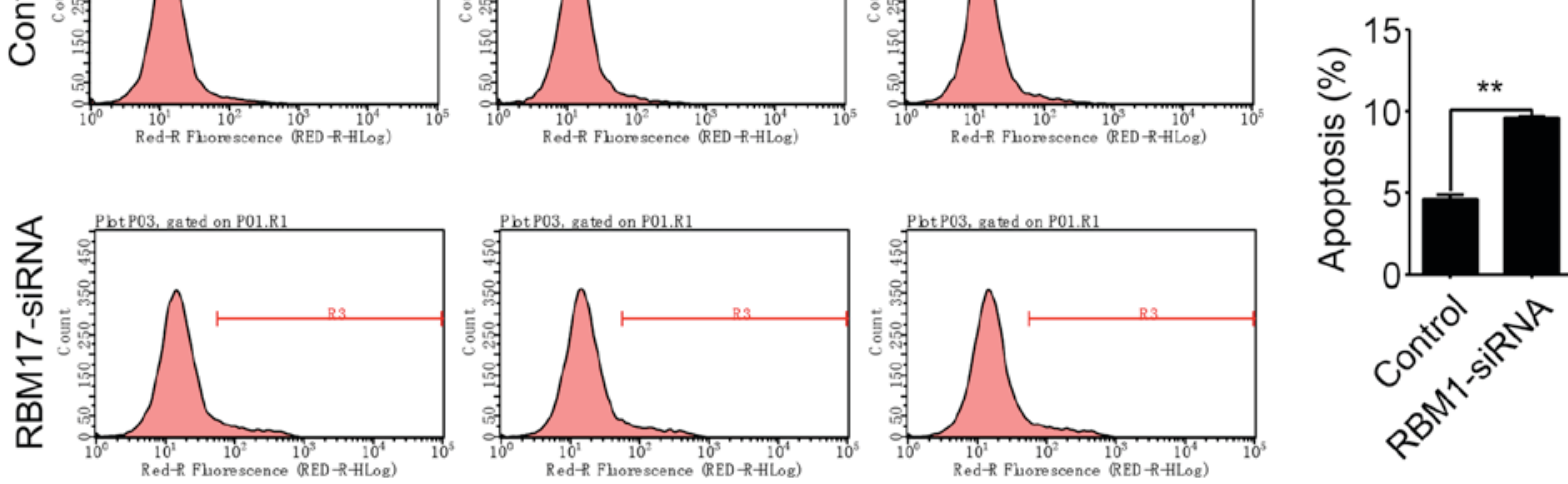

Figure 4. Effects of RBM17-shRNA transfection on cell apoptosis. (A) Cell death was determined by annexin V staining and flow cytometry. (B) Apoptosis was increased in cells infected with RBM17-shRNA compared with control cells ( $(* * \mathrm{P}<0.01)$. RBM17, RNA binding motif protein 17; siRNA, small interfering RNA.

that RBM17 protein levels were reduced in cells infected with RBM17-siRNA compared with control cells ( $\mathrm{P}<0.01$; Fig. $1 \mathrm{C})$.

Knockdown of RBM17 inhibits growth of hypopharyngeal carcinoma cells. To analyze the effect of regulation of RBM17 levels on the proliferation of hypopharyngeal carcinoma cells, the aforementioned $\mathrm{FaDu}$ cells infected with lentivirus were analyzed by Cellomics every day for 5 days. Results from day 4 and 5 of the assay revealed that proliferation of $\mathrm{FaDu}$ cells was significantly inhibited $(\mathrm{P}<0.01$; Fig. 2$)$, indicating that knockdown of $R B M 17$ reduces the proliferative ability of hypopharyngeal carcinoma cells.

Downregulation of RBM17 increases the proportion of human hypopharyngeal carcinoma cells in $G_{2} / M$ phase. To demonstrate the effects of RBM17-knockdown on the cell cycle of hypopharyngeal carcinoma cells, a flow cytometry assay was performed. FaDu cells transfected with $R B M 17$-specific shRNA had a higher proportion of cells in $\mathrm{G}_{2} / \mathrm{M}$ phase than did the control cells $(\mathrm{P}<0.01$; Fig. 3$)$.
Knockdown of RBM17 in human hypopharyngeal carcinoma cells increases apoptosis. To observe the interplay between RBM17 and apoptosis, apoptosis was measured by flow cytometry in FaDu cells in which RBM17 was knocked down (Fig. 4A). The proportion of apoptotic FaDu cells was significantly increased in shRBM17 cells compared with control cells ( $\mathrm{P}<0.01$; Fig. 4B), indicating that RBM17 expression is a determinant of apoptosis in human hypopharyngeal carcinoma cells.

\section{Discussion}

RBM17 is part of the spliceosome complex, and is involved in the alternate splicing of mRNA with AGs at the exon/intron border (16). The expression of RBM17 is limited in the majority of normal tissues, and is high in epithelial cells and a number of types of cancer tissue (21). However, the biological function of RBM17 is poorly understood.

RBM17 has been confirmed to be overexpressed in multiple cancer types $(21,24)$. A recent study revealed that overexpression of RBM17 suppresses cell proliferation and adhesion to 
fibronectin (25). Furthermore, the overexpression of RBM17 is known to induce cell migration and invasion (26). To investigate RBM17 function in the hypopharyngeal carcinoma $\mathrm{FaDu}$ cell line, RBM17 expression was knocked down in FaDu cells. The proliferation of FaDu cells infected with RBM17-shRNA was reduced, and downregulation of RBM17 increased apoptosis in FaDu cells and the proportion of cells in $\mathrm{G}_{2} / \mathrm{M}$ phase. These findings indicate that RBM17 accelerates the growth rate of $\mathrm{FaDu}$ cells.

The results of the present study imply that RBM17 may be associated with cell cycle checkpoints responsible for maintaining genomic integrity and regulating cellular proliferation in $\mathrm{FaDu}$ cells (27). The $\mathrm{G}_{2}$ checkpoint responds to DNA damage, with cancer cells with DNA damage passing through the $S$ phase checkpoint but remaining at the $G_{2}$ phase checkpoint (28). A previous study found that RBM17 was involved in DNA repair (20). However, an increase in the proportion of cells infected with $R B M 17$-shRNA in $\mathrm{G}_{2} / \mathrm{M}$ phase in the present study indicates the association of RBM17 with the decreased DNA repair.

In summary, the present study underlines the potential roles of RBM17 in the human hypopharyngeal carcinoma $\mathrm{FaDu}$ cell line. The results of the current study indicate that knockdown of $R B M 17$ by shRNA reduces the proliferation of FaDu cells, and the knockdown of RBM17 increased the proportion of cells undergoing apoptosis and arrested the cell cycle at the $\mathrm{G}_{2} / \mathrm{M}$ phase. These findings provide the basis for further investigation of the precise mechanism by which RBM17 influences cell biology in hypopharyngeal carcinoma.

\section{Acknowledgements}

The present study was supported by the Key Project of Anhui Provincial Department of Education (grant no. KJ2015A284).

\section{Competing interests}

The authors declare that they have no competing interests.

\section{References}

1. Gooi Z, Fakhry C, Goldenberg D, Richmon J and Kiess AP; Education Committee of the American Head and Neck Society (AHNS): AHNS Series: Do you know your guidelines? Principles of radiation therapy for head and neck cancer: A review of the National Comprehensive Cancer Network guidelines. Head Neck 38: 987-992, 2016.

2. Lewis CM, Hessel AC, Roberts DB, Guo YZ, Holsinger FC, Ginsberg LE, El-Naggar AK and Weber RS: Prereferral head and neck cancer treatment: Compliance with national comprehensive cancer network treatment guidelines. Arch Otolaryngol Head Neck Surg 136: 1205-1211, 2010.

3. Hong YM, Gan WG and Xu ZH: Significance of the expression of integrin $\beta 1$, VEGF and MVD in hypopharyngeal squamous cell carcinoma. Genet Mol Res 13: 6455-6465, 2014.

4. Zvrko E, Mikic A and Vuckovic L: Clinicopathologic significance of CD105-assessed microvessel density in glottic laryngeal squamous cell carcinoma. Auris Nasus Larynx 37: 77-83, 2010.

5. Chien CY, Su CY, Hwang CF, Chuang HC, Hsiao YC, Wu SL and Huang CC: Clinicopathologic significance of CD105 expression in squamous cell carcinoma of the hypopharynx. Head Neck 28: 441-446, 2006

6. Ge N, Lin HX, Xiao XS, Guo L, Xu HM, Wang X, Jin T, Cai XY, Liang Y, Hu WH and Kang T: Prognostic significance of Oct4 and Sox 2 expression in hypopharyngeal squamous cell carcinoma. J Transl Med 8: 94, 2010.
7. Kotwall C, Sako K, Razack MS, Rao U, Bakamjian V and Shedd DP: Metastatic patterns in squamous cell cancer of the head and neck. Am J Surg 154: 439-442, 1987.

8. Milisavljevic D, Stankovic M, Zivic M, Popovic M and Radovanović Z: Factors affecting results of treatment of Hypopharyngeal Carcinoma. Hippokratia 13: 154-160, 2009.

9. Chu PY, Wang LW and Chang SY: Surgical treatment of squamous cell carcinoma of the hypopharynx: Analysis of treatment results, failure patterns, and prognostic factors. J Laryngol Otol 118: 443-449, 2004.

10. Chu PY and Chang SY: Reconstruction of the hypopharynx after surgical treatment of squamous cell carcinoma. J Chin Med Assoc 72: 351-355, 2009.

11. Black DL: Protein diversity from alternative splicing: A challenge for bioinformatics and post-genome biology. Cell 103: 367-370, 2000.

12. Zheng S: IRAS: High-throughput identification of novel alternative splicing regulators. Methods Enzymol 572: 269-289, 2016.

13. Hastings ML and Krainer AR: Functions of SR proteins in the U12-dependent AT-AC pre-mRNA splicing pathway. RNA 7: 471-482, 2001.

14. Manley JL and Tacke R: SR proteins and splicing control. Genes Dev 10: 1569-1579, 1996.

15. Mayeda A, Munroe SH, Cáceres JF and Krainer AR: Function of conserved domains of hnRNP A1 and other hnRNP A/B proteins. EMBO J 13: 5483-5495, 1994.

16. Neubauer G, King A, Rappsilber J, Calvio C, Watson M, Ajuh P, Sleeman J, Lamond A and Mann M: Mass spectrometry and EST-database searching allows characterization of the multi-protein spliceosome complex. Nat Genet 20: 46-50, 1998.

17. Lallena MJ, Chalmers KJ, Llamazares S, Lamond AI and Valcárcel J: Splicing regulation at the second catalytic step by Sex-lethal involves 3' splice site recognition by SPF45. Cell 109: 285-296, 2002.

18. Silverman EJ, Maeda A, Wei J, Smith P, Beggs JD and Lin RJ: Interaction between a $\mathrm{G}$-patch protein and a spliceosomal DEXD/H-box ATPase that is critical for splicing. Mol Cell Biol 24: 10101-10110, 2004.

19. Svec M, Bauerová H, Pichová I, Konvalinka J and Strísovský K: Proteinases of betaretroviruses bind single-stranded nucleic acids through a novel interaction module, the G-patch. FEBS lett 576: 271-276, 2004.

20. Chaouki AS and Salz HK: Drosophila SPF45: A bifunctional protein with roles in both splicing and DNA repair. PLoS Genet 2: e178, 2006

21. Sampath J, Long PR, Shepard RL, Xia X, Devanarayan V, Sandusky GE, Perry WL III, Dantzig AH, Williamson M, Rolfe M and Moore RE: Human SPF45, a splicing factor, has limited expression in normal tissues, is overexpressed in many tumors, and can confer a multidrug-resistant phenotype to cells. Am J Pathol 163: 1781-1790, 2003.

22. Sakoda T, Kasahara N, Hamamori Y and Kedes L: A high-titer lentiviral production system mediates efficient transduction of differentiated cells including beating cardiac myocytes. J Mol Cell Cardiol 31: 2037-2047, 1999.

23. Livak KJ and Schmittgen TD: Analysis of relative gene expression data using real-time quantitative PCR and the 2(-Delta Delta C(T)) method. Methods 25: 402-408, 2001.

24. Perry WL III, Shepard RL, Sampath J, Yaden B, Chin WW, Iversen PW, Jin S, Lesoon A, O'Brien KA, Peek VL, et al: Human splicing factor SPF45 (RBM17) confers broad multidrug resistance to anticancer drugs when overexpressed-a phenotype partially reversed by selective estrogen receptor modulators. Cancer Res 65: 6593-6600, 2005.

25. Al-Ayoubi AM, Zheng H, Liu Y, Bai T and Eblen ST: Mitogen-activated protein kinase phosphorylation of splicing factor 45 (SPF45) regulates SPF45 alternative splicing site utilization, proliferation, and cell adhesion. Mol Cell Biol 32: 2880-2893, 2012.

26. Liu Y, Conaway L, Rutherford Bethard J, Al-Ayoubi AM, Thompson Bradley A, Zheng H, Weed SA and Eblen ST: Phosphorylation of the alternative mRNA splicing factor 45 (SPF45) by Clk1 regulates its splice site utilization, cell migration and invasion. Nucleic Acids Res 41: 4949-4962, 2013.

27. Kuntz K and O'Connell MJ: The G(2) DNA damage checkpoint: Could this ancient regulator be the Achilles heel of cancer? Cancer Biol Ther 8: 1433-1439, 2009.

28. Bucher N and Britten CD: G2 checkpoint abrogation and checkpoint kinase-1 targeting in the treatment of cancer. Br J Cancer 98: 523-528, 2008. 